\title{
STUDY ON PROJECT MANAGEMENT IN EMOTIONAL INTELLIGENCE
}

\author{
Dr. Ken Rabac \\ Amity College Florida, USA \\ dr.kjazz@gmail.com \\ Dr. Deepak Jain* \\ Amity College Florida, USA \\ prof.djain@gmail.com
}

\begin{abstract}
The regularly focused on solitary credits that sway a leader's adequacy. This investigation, all things considered, takes a gander at whether emotional intelligence directs the expected adverse consequence of appropriated presence on commitment and impact, and at last, leader viability. Buttressed by emotional intelligence, commitment, and impact speculations, the exploration question focused on how emotional intelligence abilities moderate the effect of a project supervisor's disseminated presence to deliver the leader powerful. The investigation test for this exploration came from deliberate members who work for a U.S. government office including leaders co-situated with their groups and conveyed presence leaders. Elucidating insights showed that leaders with higher emotional intelligence (EI) were more captivating and compelling than co-found leaders with high El. Relapse investigations showed most noteworthy importance between the reliant factors commitment and impact and the autonomous factors of disseminated presence and emotional intelligence when utilizing emotional intelligence branches and undertakings for the El factors. Information from this examination showed appropriated presence leaders with high emotional intelligence capacities impact commitment and impact decidedly. Crafted by this examination propels bits of knowledge into how emotional intelligence impacts, decidedly, project leader commitment and impact when the project administrator's quality is dispersed. The information delivered by this exploration was enlightening however just partly on the grounds that outcomes were not adequately broad. In any case, the use of this investigation applies to the down to earth world as dispersed groups is by all accounts a more perpetual piece of the business scene than impermanent, and figuring out how to more readily fill in as a project supervisor with disseminated presence is fundamental for the two associations and project chiefs.
\end{abstract}

Keyword: management, emotional intelligence

\section{INTRODUCTION}

Is a leader's adequacy affected by whether they cooperate with devotees face to face or through correspondence innovation? In the event that driving a good ways off is really difficult, does a leader's emotional intelligence matter in how well they can utilize innovation to lead groups a ways off? The reason for this writing survey is to recognize examines that have investigated the degree to which a leader's emotional intelligence and dispersed presence influences their apparent viability. I'm especially keen on the likelihood that a leader's emotional intelligence could direct the expected negative impact on apparent adequacy.

As a result of the distance between project destinations and the accessibility of HR, globally focused and based organizations rive the requirement for execution of virtual groups as opposed to remaining with the conventional co-found groups (Kuruppuarachchi, 2006). Projects do keep on being executed 
in the customary way of project administrator driving the project group through the life-pattern of the project until the assistance or item is delivered where both the project director and the project collaboration in a similar space, or communicate, face to face, as often as possible. Nonetheless, with the nonstop development and advances in data innovation alongside the development of organizations working universally, virtual projects and project groups are increasingly normal.

These conditions (disseminated project locales, accessibility of the human asset, and global business) encouraging virtual groups in the present workplace demonstrate a pattern as well as another standard for how work and projects will be directed. Indeed, estimates are that 1.3 billion individuals will work basically in the coming years, which is in accordance with what Johns and Gratton (2013) allude to as the "third wave" in the shift to working for all intents and purposes.

The test of conquering the project supervisor/leader's separation from the group just as disseminated presence is clear (Kossler and Prestridge, 2003). Zander, Zettinig, and Mäkelä (2013) characterized a portion of the troubles that normally exist because of scattered presence made from global virtual groups as objective arrangement, information move, and inspiration. It follows that directing the impact of the leader's conveyed presence is fundamental for the leader stays compelling paying little heed to every day presence with the project group or not. An expertise that has shown some capacity to support execution or lead to project achievement is emotional intelligence (Quisenberry, 2018). How or if emotional intelligence directs a leader's disseminated presence yet empowers the leader to be successful has not been altogether considered.

\section{OBJECTIVE OF THE STUDY}

1. To determine the difficulties of project management.

2. To examine the underutilized apparatus of project management in emotional intelligence.

\section{CHALLENGES OF PROJECT MANAGEMENT}

"A lot of worldwide senior chiefs consider project management as basic or to some degree significant" to conveying fruitful projects and accomplishing an upper hand (Project Management Institute, 2011). With project management at the center of this exploration investigating the principal parts of project management like a project, project structure, and other project angles are considered significant for dissecting leadership viability inside project management. What is a project? Just expressed, a project is an assignment with a characterized start and end that yields an extraordinary assistance, item, or result (Heldman, 2013). Management of projects normally tumbles to a project director as the group leader with "essential duties to convey the final result (1) as per execution prerequisites, (2) inside the restrictions of the project spending plan, and (3) inside the time plan his organization or client indicates" (Gaddis, 1959, p. 91). The designs that project supervisors and their project groups use are project-based, coordinated by useful regions, and composed through project management office (PMO) structures that carry out straight connections (Thiry, 2007).

It's anything but, a typical, wanted end-state is available across project management-making project progress. In this way, what is achievement? De Wit (1988) takes note of that a project may in any case be viewed as a triumph regardless of whether it has timetable and cost invades when the ideal outcome is accomplished. The points of view of various partners through the project life-cycle bringing about a viewpoint of achievement that back and forth movements during the project likewise characterize project achievement (Özdemir Gungor and Gözlü, 2016). Subsequently, with the steadily advancing conditions and requests of the business world (worldwide rivalry, complex client requests, quickly evolving innovation, new business drives, and evolving abilities) project management should likewise change (Boznak, 1996) if achievement is to be accomplished. 


\section{ENGAGEMENT}

Since groups are an always developing technique for association that organizations use to finish jobs, offer types of assistance, or foster items a superior comprehension of key parts of driving and dealing with a group is fundamental (Boznak, 1996). HR are a piece of any group: virtual or co-found. A relationship exists between leaders/project directors and colleagues where commitment is frequently considered "the anchor" (Lauren and Schreiber, 2018). A drew in group or commitment is characterized as a "positive, satisfying, business related perspective described by force, devotion, and retention" in one's work (Schaufeli et al., 2002). Of additional importance, submitted colleagues (representatives) are likewise viewed as occupied with their work (Brunetto et al., 2012). Along these lines, when leaders set up or cause a re-zeroing essentially in hierarchical and group objectives, they are invigorating group responsibility (Yousef, 2002) that cultivates commitment. This idea is upheld by the differentiating viewpoint of a broken group that displays noncommitted colleagues (Lencioni, 2002). It follows that submitted colleagues are locked in specialists who are higher performing (Tarver, 2010). "Drawn in work" brings about representatives encountering "positive feelings" while working (Costa, Margarida Passos, and Bakker, 2014).

\section{EFFECTIVE LEADERSHIP}

The inquiries relating to successful leadership were made to give extra input about group leader. There are a sum of five inquiries in the successful leadership segment of the study. The initial three inquiries offer five reactions between which study members may choose on a size of $1=$ Definitely yes to $5=$ Definitely not. The last two inquiries demand input from every member that will be composed in the reaction field accommodated each question. A prologue to the compelling leadership questions was given as a feature of the survey in Qualtrics. The acquaintance proposed design was with assistance guide study members in the event that inquiries or vulnerability happened while finishing the study about what is a powerful leader. Fifteen practices related with a viable leader are utilized as a component of the early on guide for members. The fifteen practices utilized for direction are explaining, arranging, observing, critical thinking, supporting, creating, perceiving, engaging, upholding change, imagining change, empowering development, working with aggregate getting the hang of, organizing, outer checking, and addressing (Yukl, 2012).

\section{EMOTIONAL INTELLIGENCE}

Emotional intelligence abilities are evaluated utilizing the Mayer-Salovey-Caruso Emotional Intelligence (MSCEIT) appraisal. The MSCEIT contains 141 inquiries that cover four related capacities separated into four branches: Perceiving Emotions, Using Emotions to Facilitate Thought, Understanding Emotions, and Managing Emotions (Mayer, Caruso, and Salovey, 2016). Six (6) example questions are furnished in Appendix F alongside the approval from Multi-Health Systems Inc. (MHS) to distribute the six example questions. The MSCEIT is controlled through MHS Systems, Inc. via a connection gave to get to the evaluation. The MSCEIT is a capacity proportion of a person's emotional intelligence. The in general MSCEIT produces a few scores broken into two significant classes or undertakings: experiential and key. The total gathering and division of how scores will be accounted for is as demonstrated. Of note, the MSCEIT parts used to quantify capacity comprises of inquiries, pictures, and associating feelings to different faculties. Results are given as a score range (69 or less to $130+$ ) that can be categorized as one of the accompanying classes: Consider Development (69 or less); Consider Improvement (70-89); Low Average Score (90-99); High Average Score (100-109); Competent (110-119); Strength (120-129); Significant Strength (130+) (Mayer, Salovey, and Caruso, 2002)

\section{Emergence of Emotional Intelligence}

The subject of "Emotional Intelligence" (EI) is anything but a groundbreaking idea in the scholastic world. This subject has its parentages in the 20th century when Edward Thorndike is a social researcher who deals with Social Intelligence, focuses on human able social conduct. Later In 1935, 
Edgar Doll planned the main instrument for estimating shrewd social reaction in little kids. Thorndike and Doll's works propelled David Wechsler to works further in this matter and incorporate two subscales, "Comprehension" and "Picture Settings" in his trial of Cognitive Intelligence. This early determination has arisen as an establishment for definitions and contentions on El to frame a strong establishment for El's rise and advancement. From here, El has been getting a ton of consideration from that point forward and has become the subject of conversation for individuals from the social researcher across the globe. From 1990 examination on El has flourished to certain disclosures, which prompted the advancement of various models and proportions of El(Laura Wilcox, 2017). The impact of EI in various pieces of our day by day life has been explored, and the outcome demonstrated observationally by different exploration endeavors that distribute in the different diary. These days, El has become a fundamental mantra for present-day associations and become the most loved subject for social researchers. This article is a push to figure out how to unite Evolution, Conceptualization, and Measurement of El to the project directors and to distinguish its most fitting quantify and apply to the development business.

\section{INFORMATION TECHNOLOGY (IT) SERVICES}

The IT market conveys consistent notices for offering explicit types of assistance or set of administrations to clients. The reasoning behind this current project's emphasis on the IT administration space is to underscore the Project Manager's cooperations with the clients. In any case, what does this term "administration" mean? Lamentably, the expression "administrations" as characterized by organizations, doesn't have a standard definition or significance (Bandy 2003; Svensson 2006), however it has explicit expectation(s) or a dream to a client (Koh et al. 2005; Quinn 1994; Seth et al. 2006). This is valid in all help ventures including the IT field. One piece of the organization may create the item or items, while another piece of the association offers help by means of an assistance work area or self-administration page. For this examination, the creator centers around IT benefits that require information on an IT space or region. This doesn't infer an assistance work area, where administration is predominately prearranged or the essential undertaking is to catch the data and afterward give it's anything but a more experienced help individual (Koh et al. 2005). This exploration centers around projects where the IT Project Manager is managing clients for something other than a telephone discussion. It will zero in on administrations where information on the IT area and a relationship with the client are pertinent. This incorporates information base help, application advancement, compositional arrangements, IT Security, and so on

\section{SOCIAL AND EMOTIONAL SKILLS}

Social and emotional abilities certainly appear to be the more significant leader abilities. PMI, for instance, in its 6th release Project Management Book of Knowledge (PMBOK), records emotional intelligence as an insightful speculation for project directors to make to improve themselves as well as one that yields more viable project groups (PMI, 2017). Other writing arranged these basic abilities to progress as "relationship building abilities" - compelling correspondence, the capacity to explore social connections and social connections (Riggio and Reichard, 2008). It is obvious that paying little heed to how these abilities for compelling leadership are referred to, their basic strength sits on emotional intelligence. Daniel Goleman validated this position while expressing viable leaders have one regular quality-emotional intelligence (Natemeyer and Hersey, 2011). This assumption is held by different scientists who note project administrators having emotional intelligence can be ascribed to compelling abilities that lead to positive outcomes (Boyatzis et al., 2000; Brackett, Rivers, and Salovey, 2011; Stubbs Koman, Boyatzis, and Wolff, 2008). 


\section{MEASURES OF EI}

Social researcher has made an assortment of instrument to measure the El over the earlier decade, in the different association is accessible on the lookout. On account of profound interest in the significance of estimating an individual's El level, some estimation techniques are made. This strategy for estimation is persistently changing every once in a while and is planned by the propensity of the scientist to explore. The Consortium for Research on Emotional Intelligence in Organizations (CREIO) has recorded a couple of instruments, which are created over long stretches of investigates on human $\mathrm{El}$, upheld by a resulting collection of exploration. Recorded measures are:

1. Bar-On Emotional Intelligence Quotient (EQ-I)

2. Emotional Competency Inventory 360 (ECI 360)

3. Genos El Assessment Scale (GENOS EI)

4. Mayer Salovey Caruso Emotional Intelligence Test (MSCEIT)

5. Schutte Self-Report Inventory (SSRI)

6. Trait Emotional Intelligence Questionnaire (TEIQue) 7. Wong's Emotional Intelligence Scale

In sociology that reviews the technique for estimating $\mathrm{El}$, the estimation strategy has developed quickly. Occasionally, they routinely update their El test techniques as indicated by the new climate and the most recent scholastic discoveries. Clients who need to utilize this test strategy should settle on a cautious decision dependent on their reasonableness and their work space so the outcomes will give an exact picture and can apply to the business. Various businesses need diverse evaluation techniques. The consideration of specialists was attracted to the correlation of proportions of El, looking for the best and appropriate instrument to use on development project administrators.

\section{Practical contribution}

Higher project disappointment rates as far as time and cost in the Indian development industry have brought about numerous unfavorable impacts including high wastage, more capital venture that ought to be, wastage of public assets, postponed arranging as late in property possession and foundation use, contaminating the standing of development specialists so they need to drag the court. These variables are for the most part horrendous for the business, and it shakes the certainty of unfamiliar financial backers to put resources into India. This point isn't something that we should feel great, yet it should be set out to discover answers for the way that India's development industry is trusted and regarded locally as well as around the world.

\section{CONCLUSION}

While additionally a shortcoming, is the investigation centers altogether around a particular organization. Like this investigation, future examinations could zero in on the emotional intelligence abilities of project leaders who lead in conveyed presence conditions or virtual groups yet in offices or organizations that offer a more extensive information test (an ever increasing number of demographically assorted representatives). From the bigger information test, more conclusive outcomes are relied upon to address the inquiries regarding the impact of a leader's conveyed presence on commitment and impact, and the directing impact of emotional intelligence on project leader dispersed presence. The outcomes could then be utilized to offer more substantial mindfulness for limiting the adverse consequences of project leader dispersed presence. Any extra examinations ought to likewise endeavor to be coordinated in a way that guarantees the more strong example of project leaders and colleagues can be all the more handily related to all the more broadly explore the job of emotional intelligence in the project leader-supporter relationship. It would be similarly intriguing to utilize a more extensive information test as a piece of an office's leadership advancement program with a focus on emotional intelligence abilities that exist inside the association, and how to additionally foster both slacking and created emotional intelligence abilities. For instance, controlling a pre-improvement appraisal of leader and devotee El capacities would set up the standard of leader commitment and impact, for instance, before formative preparing happens. Post-advancement 
evaluation of El capacities alongside leader commitment and impact would give plainly characterized measures to progress identified with El capacities.

\section{REFERENCES}

[1]. Adler, N. J. (2002). International dimensions of organizational behavior (4th ed.). Cincinnati, $\mathrm{OH}$ : South-Western.

[2]. Bhattacherjee, A. (2012). Social science research: principles, methods, and practices (Second ed.). Tampa, FL: University of South Florida.

[3]. Caldwell, C. (2016). A case study exploring leadership, work team engagement, and safety performance in a high-risk work enviornment. (Doctor of Philosophy), Fielding Graduate University, Ann Arbor, MI.

[4]. de Wit, A. (1988). Measurement of project success. International Journal of Project Management, 6, 164-170. doi:10.1016/0263-7863(88)90043-9

[5]. Emotional intelligence "wow" factor. (2012). Development and Learning in Organizations: An International Journal, 27(1), 25-27. doi:10.1108/14777281311291268

[6]. Foltin, A., \& Keller, R. (2012). Leading change with emotional intelligence: What happens when a hospital unit is faced with seemingly insurmountable challenges in a short period of time? Nursing Management, 43(11), 20-25. doi:10.1097/01.NUMA.0000421675.33594.63

[7]. Gentner, D. (1983). Structure-mapping: A theoretical framework for analogy. Cognitive Science, 7(2), 155-170. doi:10.1207/s15516709cog0702_3

[8]. Hanges, P. J., Aiken, J. R., Park, J., \& Su, J. (2016). Cross-cultural leadership: leading around the world. Current Opinion in Psychology, 8, 64-69. doi:https://doi.org/10.1016/j.copsyc.2015.10.013

[9]. Job crafting in organizations: What can it mean for your workplace? (2016). Leader to Leader(81), 58. doi:10.1002/Itl.20247

[10]. Kuruppuarachchi, P. (2006). Managing virtual project teams: how to maximize performance. Handbook of Business Strategy, 7(1), 71-78. doi:10.1108/10775730610618648

[11]. Lauren, B., \& Schreiber, J. (2018). An integrative literature review of project management in technical and professional communication. Technical Communication, 65(1), 85-106.

[12]. Malhotra, A., Majchrzak, A., \& Rosen, B. (2007). Leading virtual teams. Academy of Management Perspectives, 21(1), 60-70. doi:10.5465/AMP.2007.24286164.

[13]. Rodriguez, L. F. (2015) "Practical Guidelines for the Practice of Knowledge Management in Higher Education", IARS' International Research Journal. Vic. Australia, 5(2). doi: 10.51611/iars.irj.v5i2.2015.51.

[14]. Upadhayaya, V. (2017) "Emotional Dynamics of Action and Core Involvement: A new theoretical perspective for designing development strategies in schools", IARS' International Research Journal. Vic. Australia, 7(2). doi: 10.51611/iars.irj.v7i2.2017.79. 


\begin{tabular}{|l|l|}
\hline \multicolumn{2}{|c|}{ Editorial Processing Record } \\
\hline Date of Submission: & $17-$ Oct-2021 \\
\hline Date of Final Review: & $16-$ Nov-2021 \\
\hline Date of Acceptance: & $02-$ Dec-2021 \\
\hline Final Processing: & $26-$ Dec-2021 \\
\hline Date of Publishing: & $29-$ Dec-2021 \\
\hline \multicolumn{2}{|c|}{ Last Plagiarism Report } \\
\hline \multicolumn{2}{|c|}{ Originality Assessment } \\
Ovall Similarity: \\
Date: Dec 26, 2021 \\
Statistics: 84 words Plagiarized / 3241 Total words \\
Remarks: Low similarity detected, check your supervisor if changes are requirec \\
\hline
\end{tabular}

